\title{
Non-fluorinated superamphiphobic surfaces through sol-gel processing of methyltriethoxysilane and tetraethoxysilane
}

\author{
Yuung-Ching Sheen ${ }^{\mathrm{a}}$, Wei-Hsuan Chang ${ }^{\mathrm{b}}$, Wen-Chang Chen ${ }^{\mathrm{b}}$, \\ Yih-Her Chang ${ }^{c}$, Yuan-Chang Huang ${ }^{c}$, Feng-Chih Chang ${ }^{a, *}$ \\ a Department of Applied Chemistry, National Chiao Tung University, Hsin Chu 30010, Taiwan \\ ${ }^{\mathrm{b}}$ Institute of Polymer Science and Engineering, National Taiwan University, Taipei, Taiwan \\ ${ }^{\mathrm{c}}$ Material and Chemical Research Laboratories, Industrial Technology Research Institute, \\ $30050 \mathrm{H} \sin \mathrm{Chu}$, Taiwan
}

\section{A R T I C L E I N F O}

\section{Article history:}

Received 9 June 2008

Received in revised form 10 July 2008

Accepted 25 July 2008

\section{Keywords:}

Superamphilopbic

Sol-gel

Silica

Nanoparticle

\begin{abstract}
A B S T R A C T
In this study, a simple approach was developed to fabricate an extremely superamphiphobic coating material by the tetraethoxysilane (TEOS) and methyltriethoxysilane (MTES) sol-gel derived materials. TEOS and MTES derived moieties were designed for a physical roughness and hydrophobic surface characteristic, respectively. The ${ }^{29} \mathrm{Si}$ solid-state NMR and ESCA analysis showed the coated silica composition was similar to the feeding ratios of TEOS/MTES. The surface structure characterized from SEM and TEM suggested the nanoparticle-based silica surface was observed at a high TEOS/MTES content but changed to a relatively smooth surface at a low TEOS content. The contact angles of water and $\mathrm{CH}_{2} \mathrm{I}_{2}$ on the pure TEOS derived coated surface were both $0^{\circ}$ due to the hydrophilic Si-OH group. As the MTES composition increased to $25 \mathrm{~mol} \%$ (T5M3), the coated surface had the contact angles of $149.8^{\circ}$ and $133.1^{\circ}$ for water and $\mathrm{CH}_{2} \mathrm{I}_{2}$, respectively. It revealed that the T5M3-coated surface exhibited both super-hydrophobicity and super-oleophobicity, i.e., superamphiphobicity. Also, it had a relatively low-surface energy $\left(1.38 \mathrm{~mJ} \mathrm{~m}^{-2}\right)$ considerably lower than that of the F-silane-coated surface with $39.3 \mathrm{~mJ} \mathrm{~m}^{-2}$. As the MTES composition increased further, both contact angles of water and $\mathrm{CH}_{2} \mathrm{I}_{2}$ decreased. Especially, they decreased dramatically at the MTES feeding composition higher than $75 \mathrm{~mol} \%$, due to the much less rough surface at a higher MTES composition. The present study suggests that superamphiphobic surface could be achieved by non-fluorinated sol-gel derived silica materials.
\end{abstract}

(c) 2008 Published by Elsevier B.V.

\section{Introduction}

Lotus effect is a well-known super-hydrophobic phenomenon observed in nature $[1,2]$. Combination of chemically hydrophobic waxy surface and physically rough micro- and nanoscale binary structure leads to the self-cleaning properties of the lotus leaf. Such super-hydrophobic phenomena was simulated by various chemical or physical surface treatments [4-17]. For example, flat man-made surfaces modified by fluoropolymers or silanes as lowsurface energy modifiers led to water contact angles as high as $120^{\circ}[3]$. Recently, super-hydrophobic surfaces based on organic-

\footnotetext{
* Corresponding author at: Department of Applied Chemistry, National Chiao Tung University, Science Building 2, Hsin Chu 30010, Taiwan. Tel.: +8863 5131512; fax: +88635723764.

E-mail address: changfc@mail.nctu.edu.tw (F.-C. Chang).
}

modified silica nanoparticle were discovered to have water contact angle larger than $150^{\circ}$ [16-20]. They were resulted from roughness based on the nanoparticle size and hydrophobic characteristic of organic moiety. The organic-modified materials included lowsurface-free-energy polybenzoxazine $[16,20]$ and fluoroalkylsilane [17-19]. However, the above organic-modified surfaces required extra organic reaction on nanoparticles and could be difficult to control the surface characteristics. Also, fluoro-materials was expensive and thus limited its commercial application. A direct sol-gel reaction to produce organic-modified nanoparticles without fluoroalkylsilane would be a simple process for obtaining superamphiphobic surfaces.

In this study, superamphiphobic surfaces prepared from the tetraethoxysilane (TEOS) and methyltriethoxysilane (MTES) sol-gel derived coating materials were explored, as shown in Scheme 1. First, sol-gel reaction on different compositions of TEOS/MTES was carried out to form the primary particle, then further gelation on 
<smiles>CCO[Si](OCC)(OCC)OCC</smiles>

Tetraethyl orthosilicate TEOS<smiles>CCO[Si](C)(OCC)OCC</smiles>

Methylethoxysilane MTES

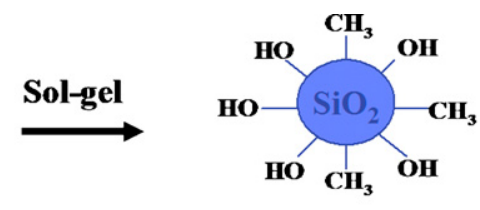

Primary Particle

Particle Size : $50 \sim 200 \mathrm{~nm}$

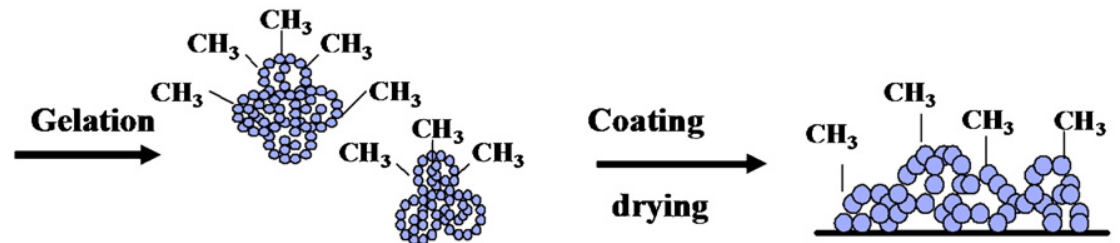

Secondary Particle

Particle Size : um

Scheme 1. Proposal mechanism of the superamphiphobic surface formed by TEOS/MTES sol-gel derived coating.

Table 1

Contact angles and surface energies of photographic paper coated with different TEOS/MTES sol-gel derived silica solution.

\begin{tabular}{|c|c|c|c|c|c|}
\hline Sample & MTES (mol\%) & Carbon $^{\mathrm{a}}$ content (at.\%) & $\mathrm{H}_{2} \mathrm{O}$ contact angle $\left({ }^{\circ}\right)$ & $\mathrm{CH}_{2} \mathrm{I}_{2}$ contact angle $\left(^{\circ}\right)$ & Surface free energy $\gamma\left(\mathrm{mJ} \mathrm{m}^{-2}\right)$ \\
\hline Unmodified paper (blank) & 0.0 & - & 36.1 & 0 & 66.9 \\
\hline F-silane-coated paper & 0.0 & - & 107.5 & 48.3 & 39.3 \\
\hline T1M0 & 0.0 & 8.0 & $-{ }^{\mathrm{b}}$ & $-{ }^{\mathrm{b}}$ & - \\
\hline T7M1 & 12.5 & 17.9 & 151.9 & $-{ }^{\mathrm{b}}$ & - \\
\hline T3M1 & 25.0 & 21.0 & 146.2 & 35.6 & 72.42 \\
\hline Т5М3 & 37.5 & 23.5 & 149.8 & 133.1 & 1.38 \\
\hline T1M1 & 50.0 & 26.4 & 147.0 & 120.8 & 3.64 \\
\hline T3M5 & 62.5 & 27.6 & 147.0 & 114.9 & 5.50 \\
\hline T1M3 & 75.0 & 32.3 & 95.4 & 68.7 & 23.93 \\
\hline T1M7 & 87.5 & 33.2 & 95.0 & 64.8 & 25.97 \\
\hline T0M1 & 100.0 & 35.5 & 98.3 & 65.3 & 25.54 \\
\hline
\end{tabular}

a The carbon content (at.\%) by the measurement of ESCA

b The liquid drop was immediately absorbed by the rough surface.

the above reaction product by adding ammonium hydroxide led to the secondary particle in solution. Next, the above sol-gel solution was coated onto photographic paper substrate and followed by drying to form the superamphiphobic surfaces. TEOS derived silica was designed for a physical roughness of micro- and nanoscale binary structures and MTES for improving hydrophobic surface characteristic. The chemical compositions of the sol-gel derived materials were analyzed by solid-state NMR and ESCA. Effects of the MTEO/TEOS composition on the morphology and surface characteristic were investigated by SEM, AFM, and contact angle measurements. The experimental results suggested such simple non-fluoroalkyl silica could produce the superamphiphobic surfaces with the contact angle of water or diiodomethane higher than that of fluoropolymer.

\section{Experimenta}

\subsection{Materials}

TEOS and MTES were obtained from Acros (New Jersey, USA) and used without further purification. Tridecafluoro-1,1,2,2,-tetrahydrooctyl-1triethoxysilane $(1 \mathrm{H}, 1 \mathrm{H}, 2 \mathrm{H}, 2 \mathrm{H}$-perfluorooctyltriethoxysilane) was supplied by the Seedchem Co. (Melbourne, Australia). 2-Amino-2-methyl-propanol (AMP95) was supplied by Neuto Products Co. (Taipei, Taiwan). Ammonium hydroxide ( $28 \mathrm{wt} \%$ ) was gained by Showa (Tokyo, Japan). Diiodomethane was supplied by Lancaster (Lancashire, UK). Isopropyl alcohol (IPA), ethanol and acetic acid were supplied by the Tedia Chemical Co. (Fairfield, USA).

\subsection{Preparation of TEOS/MTES sol-gel solution}

A mixture of different compositions of TEOS and MTES [molar fractions ranging from 1:0 to 0:1 (Table 1); total: $0.0192 \mathrm{~mol}$ ), AMP95 (2.26 g), ethanol (21 g), and DI water $(1.05 \mathrm{~g})$, were added to $50 \mathrm{ml}$ capped glass bottle under vigorous stirring at room temperature for $1 \mathrm{~h}$. Then, another $2.26 \mathrm{~g}$ of ammonium hydroxide ( $28 \mathrm{wt} \% \mathrm{in}$ water) was added under vigorous stirring at room temperature for $6 \mathrm{~h}$. As examples of the nomenclature used in this study, T1M0 and T7M1 refer to the samples prepared from 1:0 and 7:1 molar ratios of TEOS and MTES for preparing the above precursor solutions, respectively.

\subsection{Preparation of superamphiphobic surfaces}

The above TEOS/MTES sol-gel derived silica solution (in ethanol) were coated onto a photographic paper (purchased from Printer Co., Taiwan) by doctor blade

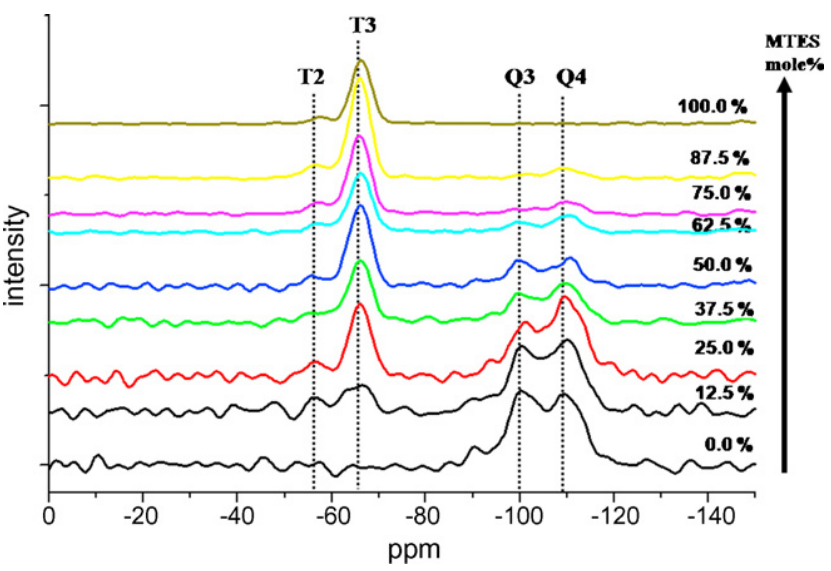

Fig. 1. Solid-state ${ }^{29} \mathrm{Si}$ NMR spectra of the sol-gel derived silica from different TEOS/MTES compositions. 

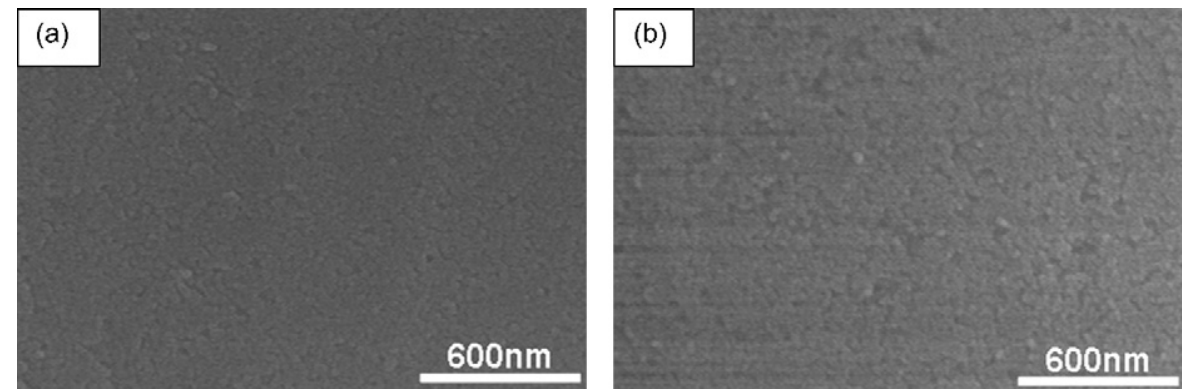

Fig. 2. SEM images of the (a) blank and (b) F-silane-coated photographic paper substrate.
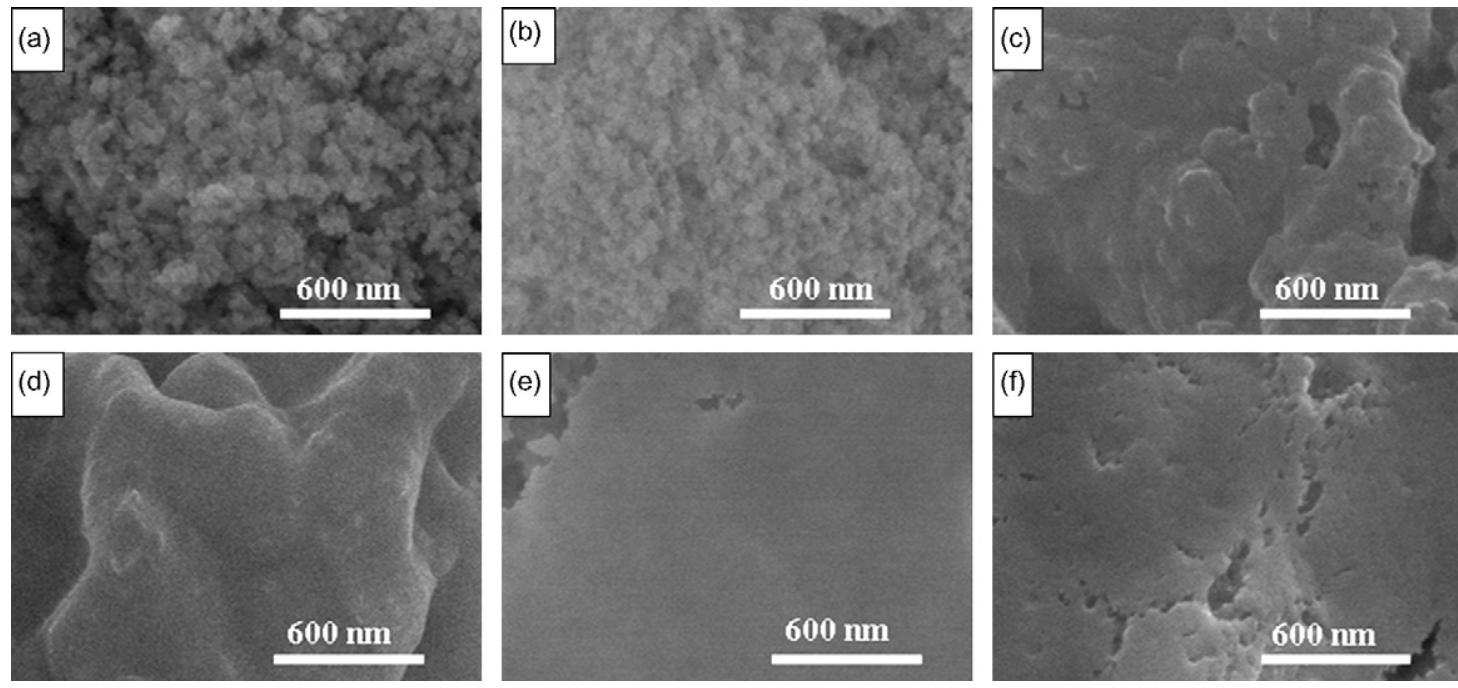

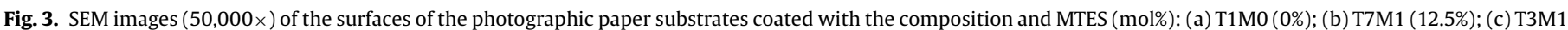
(25\%); (d) T1M1 (50\%); (e) T1M3 (75\%); (f) T1M7 (87.5\%) silica.

and put into oven for drying at $120^{\circ} \mathrm{C}$ for $1 \mathrm{~h}$ to form the super-hydrophobic and superamphiphobic silica surfaces. The coated silica thickness on the surface was around $500 \mu \mathrm{m}$.

\subsection{Preparation of F-silane-coated surface for comparison}

A mixture of $1 \mathrm{H}, 1 \mathrm{H}, 2 \mathrm{H}, 2 \mathrm{H}$-perfluorooctyltriethoxysilane $(0.95 \mathrm{~g}(0.00185 \mathrm{~mol}))$ IPA ( $30 \mathrm{~g})$, DI water $(1.58 \mathrm{~g})$, and acetic acid $(100 \mu \mathrm{l}, 0.00175 \mathrm{~mol})$ were added to $50 \mathrm{ml}$ of capped glass bottle under vigorous stirring at room temperature for $24 \mathrm{~h}$. The above F-silane (PFS) solution was then coated onto a photographic paper substrates by dipping process and put into oven at $120^{\circ} \mathrm{C}$ for $1 \mathrm{~h}$ to obtain the PFS coated surface.

\subsection{Characterization}

Solid-state ${ }^{29} \mathrm{Si}$ NMR spectra were recorded at room temperature using a Bruker AM 500 spectrometer. The sample was ground to a fine powder and then placed into the NMR tube. Chemical compositions of the substrate surface were analyzed using a Thermo VG Scientific ESCALAB 250 spectrometer equipped with a monochromatic $\mathrm{Al} \mathrm{K} \alpha \mathrm{X}$-ray source (1486.6 eV photons), the vacuum in the analysis chamber was maintained at ca. $10-8$ mbar or lower.

Microstructure of the prepared silica surfaces was characterized using a Hitachi S-4200 scanning electron microscope. Atomic force microscopy (AFM) images were acquired using a Veeco MultiMode scanning probe microscope. Damage to both the tip and the sample surface was minimized by employing the AFM in the tapping mode. The values of root-mean-square (RMS) roughness were calculated over scan area of $10 \mu \mathrm{m} \times 10 \mu \mathrm{m}$

The static contact angles of 5 - $\mu$ l liquid drops deposited on the silica surfaces were determined through contact angle goniometry at $25^{\circ} \mathrm{C}$ using an AST Products Optima XE goniometer (Billerica, USA) interfaced with image-capture software. To obtain reliable contact data, at least three droplets were placed on different regions of at least two pieces of film. The surface free energy was estimated according to those reports by Owens and Wendt [21] and Kaelble and Uy [22] and given below briefly. The work equation extended from Fowkers' equation to a geometric mean method is given by

$\gamma_{i}\left(1+\cos \theta_{i}\right)=2\left(\sqrt{\gamma_{i}^{\mathrm{d}} \gamma_{\mathrm{s}}^{\mathrm{d}}}+\sqrt{\gamma_{i}^{\mathrm{p}} \gamma_{\mathrm{s}}^{\mathrm{p}}}\right), \quad i=1,2$

$\theta_{i}$ and $\gamma_{i}$ refer to contact angle and surface free energy of liquid 1 and liquid 2 , respectively. $\gamma_{i}^{\mathrm{d}}, \gamma_{i}^{\mathrm{p}}, \gamma_{s}^{\mathrm{d}}$ and $\gamma_{\mathrm{s}}^{\mathrm{p}}$ are assumed to refer to dispersion (nonpolar) forces and polar (nondispersion) forces between the liquid and solid phases.

\section{Results and discussion}

Fig. 1 exhibits the solid-state ${ }^{29}$ Si NMR spectra of the TEOS/MTES derived materials. The peak positions of $\mathrm{Q} 4, \mathrm{Q} 3, \mathrm{~T} 3$, and $\mathrm{T} 2$ of TEOS/MTES derived materials are observed at $-109.3,-100.3$,

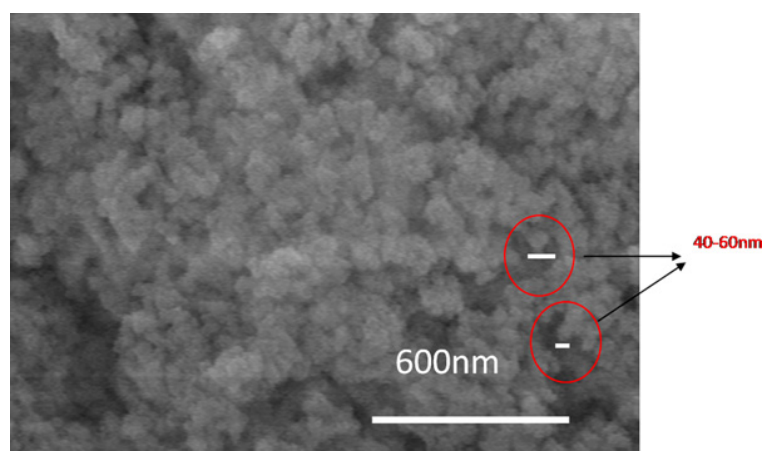

Fig. 4. SEM image of the surfaces of the photographic paper substrates coated with the sol-gel derived material, T1M0 (0\%).

Please cite this article in press as: Y.-C. Sheen, et al., Non-fluorinated superamphiphobic surfaces through sol-gel processing of methyltriethoxysilane and tetraethoxysilane, Mater. Chem. Phys. (2008), doi:10.1016/j.matchemphys.2008.07.132 


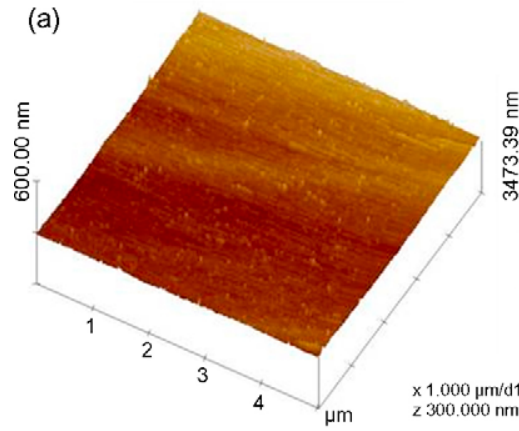

RMS $10.77 \mathrm{~nm}$

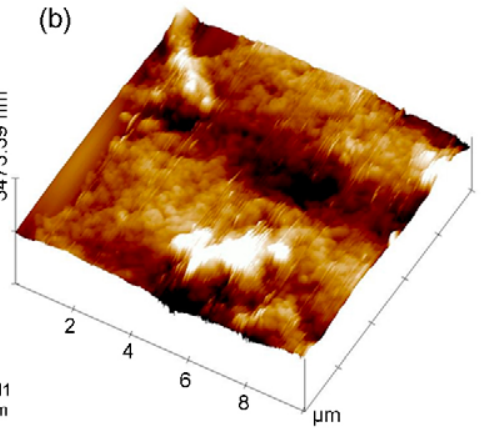

RMS $140.12 \mathrm{~nm}$

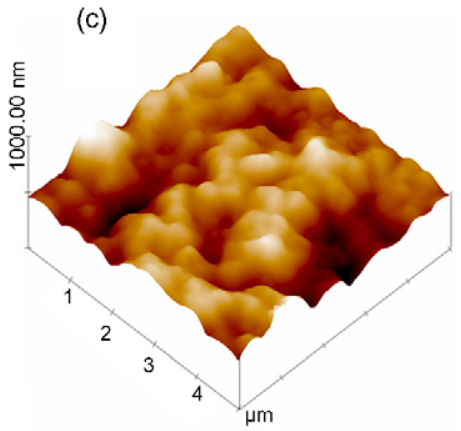

RMS $21.24 \mathrm{~nm}$

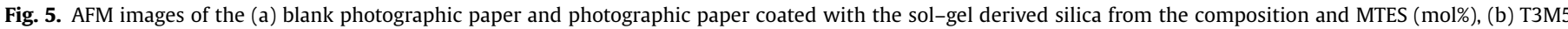
(37.5\%), and (c) T1M3 (75\%).

-66.2 and $-57.0 \mathrm{ppm}$, respectively, which are similar to those reported in the literature. As shown in Fig. 1, the peak intensities of the Q3 and Q4 decrease with increasing the MTES content while the peak intensities of $\mathrm{T} 2$ and $\mathrm{T} 3$ show a reverse trend. It suggests that the synthesized material compositions are similar to those of the feeding mole ratios of TEOS/MTES.
The TEOS/MTES silica derived composition on surface was further characterized by ESCA. We observed photoemission peaks from the F 1s, O 1s, C $1 \mathrm{~s}$, and Si 2 p core levels together with Auger structures related to elemental carbon, oxygen, and fluorine species. In the following, the atomic percentage of carbon (Table 1) was estimated from the elemental concentrations represented by
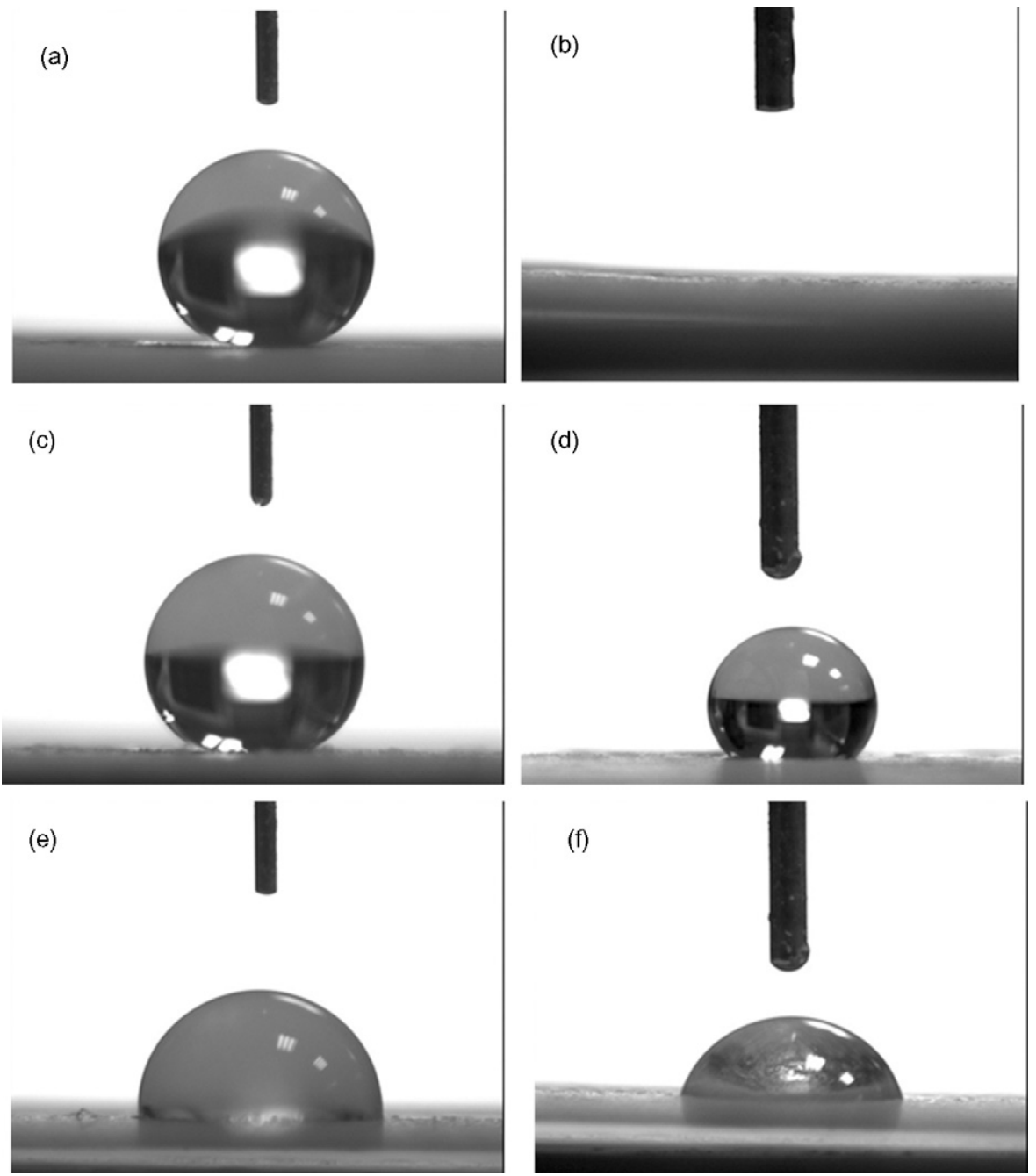

Fig. 6. Photographs of liquids water ( $5 \mu \mathrm{l}$ ) placed on the silica-coated substrate and the composition and MTES (mol\%): (a) T7M1 (12.5\%), (c) T5M3 (37.5\%), and (e) T0M1 (100\%); $\mathrm{CH}_{2} \mathrm{I}_{2}(5 \mu \mathrm{l})$ on the silica-coated substrate: (b) T7M1 (12.5\%), (d) T5M3 (37.5\%), and (f) T0M1 (100\%).

Please cite this article in press as: Y.-C. Sheen, et al., Non-fluorinated superamphiphobic surfaces through sol-gel processing of methyltriethoxysilane and tetraethoxysilane, Mater. Chem. Phys. (2008), doi:10.1016/j.matchemphys.2008.07.132 


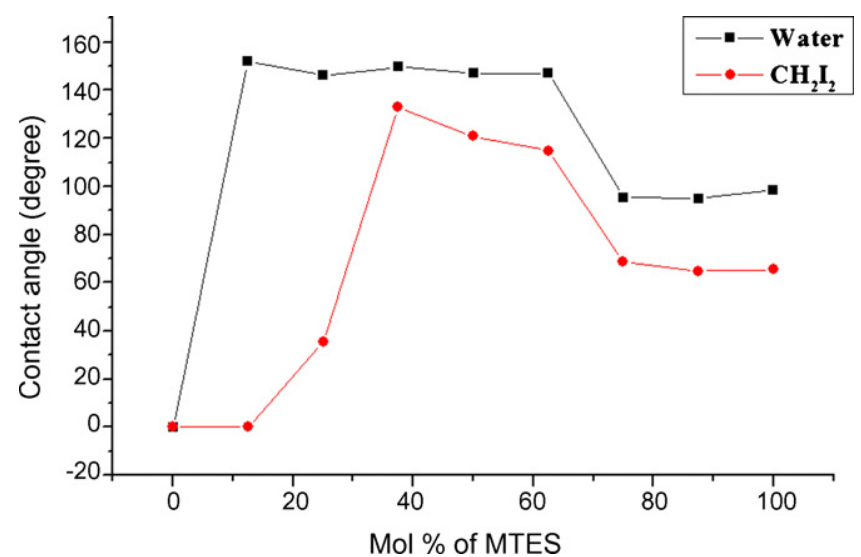

Fig. 7. Contact angles of photographic paper substrates coated with sol-gel derived silica from different compositions of TEOS/MTES.

the C $1 \mathrm{~s}, \mathrm{O} 1 \mathrm{~s}, \mathrm{~F} 1 \mathrm{~s}$, and $\mathrm{Si} 2 \mathrm{p}$ core energy levels. The obtained carbon content vary from 0 to 35.5 at.\% as the MTES feeding composition increases from $0 \%$ (T1M0) to $100 \%$ (T0M1). It again shows that the coated composition on the surface is on the trend as the original feeding composition.

The surface structures were analyzed by SEM and AFM. As a basis for comparison, the surface characteristics of the blank paper substrate and F-silane-coated surface were studied first. Fig. 2(a) and (b) shows the SEM images of the blank and F-silane-coated photographic papers, respectively. Both images are smooth with contact angles of $36.1^{\circ}$ and $107.5^{\circ}$ for water, respectively, while the corresponding surface free energies of 66.9 and $39.3 \mathrm{~mJ} \mathrm{~m}^{-2}$. It is as expected that the F-silane-modified surface of the photographic paper had a higher contact angle and a lower surface energy than the blank.

Fig. 3 shows the SEM images $(50,000 \times)$ of the photographic paper coated with the different compositions of sol-gel derivated silica: (a) T1M0; (b) T7M1; (c)T3M1; (d) T1M1; (e) T1M3; (f) T1M7, respectively. As shown in Fig. 4, silica nanoparticle with the estimated sizes around $40-60 \mathrm{~nm}$ is clearly observed. Such nanoparticle-based rough surface gradually becomes smooth as the MTES content increases. Note that the SEM image of the TOM1 coated sample could not be obtained due to the poor film quality. Fig. 5 shows the AFM images of the (a) blank paper substrate, that coated with the (b) T3M5, and (c) T1M3 sol-gel derived silica. The root-mean-square surface roughness estimated from the above AFM images are $10.77,140.12$, and $21.24 \mathrm{~nm}$, respectively. It suggests that a lower TEOS/MTES ratio leads to a less rough surface. The above variation on the SEM and AFM images is explained as below. Silica nanoparticles synthesized from tetra-functional TEOS sol-gel reaction generally exhibits a three-dimension microstructure with hydrophilic $\mathrm{OH}$ groups on the surfaces. However, the tri-functional MTES may have a two-dimension planar structure with hydrophobic $\mathrm{CH}_{3}$ groups on the silica surfaces. Such variation on the surface structure would be important for obtaining optimum TEOS/MTES composition to create the superamphiphobic surface.

The static contact angle measurement was used to characterize the hydrophobicity and oleophobicity of the TEOS/MTES derived silica surfaces. Contact angle measurements reflect the characteristics of the interface between the coating film and the probe liquid, including both the thermodynamic parameters and the surface roughness. In this measurement, drops of water and $\mathrm{CH}_{2} \mathrm{I}_{2}$ were placed directly upon the rough surfaces, as shown in Fig. 6. The variation of contact angle with different TEOS/MTES coating compositions is shown in Fig. 7 and Table 1. The contact angles of water and $\mathrm{CH}_{2} \mathrm{I}_{2}$ on the T1M0-coated film were both $0^{\circ}$ (i.e., complete wetting of the surface), due to the hydrophilic $\mathrm{Si}-\mathrm{OH}$ group on the surface. Interestingly, a dramatic increase on the water contact angle of $151.9^{\circ}$ is observed for the T7M1-coated surface (note that a value greater than $150^{\circ}$ corresponds to superhydrophobicity). However, the static contact angle for $\mathrm{CH}_{2} \mathrm{I}_{2}$ was $0^{\circ}$ for the T7M1-coated surface due to the presence of the hydrophobic $\mathrm{CH}_{3}$ groups of the MTES moiety. As the MTES composition increased to $25 \mathrm{~mol} \%$, the T5M3-coated surface had the contact angles of $149.8^{\circ}$ and $133.1^{\circ}$ for water and $\mathrm{CH}_{2} \mathrm{I}_{2}$, respectively. It reveals that the T5M3-coated surface exhibits both super-hydrophobicity and super-oleophobicity, i.e., superamphiphobicity, resulted from the rough TEOS-derived surface and hydrophobic MTES-derived surface. Also, it has a relatively low-surface energy $\left(1.38 \mathrm{~mJ} \mathrm{~m}^{-2}\right)$ considerably lower than that of F-silane-coated surface with $39.3 \mathrm{~mJ} \mathrm{~m}^{-2}$. As the MTES composition increases further, both contact angles of water and $\mathrm{CH}_{2} \mathrm{I}_{2}$ decrease. Especially, they decrease dramatically at the MTES feeding composition higher than $75 \mathrm{~mol} \%$. It can be explained by the much less rough surface at a higher MTES composition, as observed from SEM and TEM images. Nevertheless, the TOM1 (100\% MTES feeding composition) possessed a lowsurface energy of $25.54 \mathrm{~mJ} \mathrm{~m}^{-2}$, very close to the surface energy of the fluoropolymer poly(tetrafluoroethylene) (ca. $20-21 \mathrm{~mJ} \mathrm{~m}^{-2}$ ).

\section{Conclusions}

We have successfully developed a simple approach to fabricate an extremely superamphiphobic coating material by the TEOS/MTES sol-gel derived materials. The coated silica composition was similar to the feeding ratios of TEOS/MTES. The surface structure showed the nanoparticle-based silica surface was observed at a high TEOS/MTES content but changed to a relatively smooth surface at a low TEOS content through the optimization of the TEOS/MTES composition, the T5M3-coated surface with 25 mol\% of MTES had the contact angles of $149.8^{\circ}$ and $133.1^{\circ}$ for water and $\mathrm{CH}_{2} \mathrm{I}_{2}$, respectively. It exhibited both super-hydrophobicity and super-oleophobicity, i.e., superamphiphobicity, resulted from the rough TEOS-derived surface and hydrophobic MTES-derived surface. Also, it has a relatively low-surface energy $\left(1.38 \mathrm{~mJ} \mathrm{~m}^{-2}\right)$ considerably lower than that of F-silane-coated surface with $39.3 \mathrm{~mJ} \mathrm{~m}^{-2}$. The present study suggests that superamphiphobic surface could be achieved by non-fluorinated sol-gel derived silica materials.

\section{Appendix A. Supplementary data}

Supplementary data associated with this article can be found, in the online version, at doi:10.1016/j.matchemphys.2008.07.132.

\section{References}

[1] C. Neinhuis, W. Barthlott, C. Neinhuis, Ann. Bot. 79 (1997) 667.

[2] W. Barthlott, C. Neinhuis, Planta 202 (1997) 1.

[3] E.G. Shafrin, W.A. Zisman, Contact angle, wettability, and adhesion, in: F.M. Fowkes (Ed.), Advances in Chemistry Series, vol. 43, American Chemical Society, Washington, DC, 1964, p. 145.

[4] X.J. Feng, J. Zhai, L. Jiang, Angew. Chem. Int. Ed. 44 (2005) 5115

[5] M.H. Jin, X.J. Feng, L. Feng, T.L. Sun, J. Zhai, T.J. Li, L. Jiang, Adv. Mater. 17 (2005) 1977.

[6] M. Morra, E. Occhiello, F. Garbassi, Langmuir 5 (1989) 872.

[7] I. Woodward, W.C.E. Schofield, V. Roucoules, J.P.S. Badyal, Langmuir 19 (2003) 3432.

[8] K. Tsujii, T. Yamamoto, T. Onda, S. Shibuichi, Angew. Chem. Int. Ed. Engl. 9(1997) 36.

[9] T. Onda, S. Shibuichi, N. Satoh, K. Tsujii, Langmuir 12 (1996) 2125.

[10] L. Gao, T.J. McCarthy, Langmuir 24 (2008) 362.

[11] H. Yan, K. Kurogi, H. Mayama, K. Tsujii, Angew. Chem., Int. Ed. 44 (2005) 3453.

[12] X. Yu, Z. Wang, Y. Jiang, F. Shi, X. Zhang, Adv. Mater. 17 (2005) 1289.

[13] F. Xia, L. Feng, S. Wang, T. Sun, W. Song, W. Jiang, L. Jiang, Adv. Mater. 18 (2006) 432. 
[14] F. Shi, Z. Wang, X. Zhang, Adv. Mater. 17 (2005) 1005.

[15] L. Zhai, C. Fevzi, R.E. Cohen, M.F. Rubner, Nano Lett. 7 (2004) 1349.

[16] C.F. Wang, Y.T. Wang, P.H. Tung, S.W. Kuo, C.H. Lin, Y.C. Sheen, F.C. Chang, Langmuir 22 (2006) 8289.

[17] J. Bravo, L. Zhai, Z. Wu, R.E. Cohen, M.F. Rubner, Langmuir 23 (2007) 7293.

[18] M. Hikita, K. Tanaka, T. Nakamura, T. Kajiyama, A. Takahara, Langmuir 21 (2005) 7299.
[19] H.M. Shang, Y. Wang, K. Takahashi, G.Z. Cao, J. Mater. Sci. 40 (2005) 3587.

[20] C.F. Wang, S.F. Chiou, F.H. Ko, C.T. Chou, H.C. Lin, C.F. Huang, F.C. Chang, Macromol. Rapid Commun. 27 (2006) 333.

[21] D.K. Owens, R.C. Wendt, J. Appl. Polym. Sci. 13 (1969) 1741.

[22] D.H. Kaelble, K.C. Uy, J. Adhes. 2 (1970) 50. 